\title{
Complications related to deep venous thrombosis prophylaxis in trauma: a systematic review of the literature
}

\author{
Indraneel Datta ${ }^{1}$, Chad G Ball ${ }^{*}$, Lucas Rudmik¹, S Morad Hameed ${ }^{2}$, John B Kortbeek ${ }^{1}$
}

\begin{abstract}
Deep venous thrombosis prophylaxis is essential to the appropriate management of multisystem trauma patients. Without thromboprophylaxis, the rate of venous thrombosis and subsequent pulmonary embolism is substantial. Three prophylactic modalities are common: pharmacologic anticoagulation, mechanical compression devices, and inferior vena cava filtration. A systematic review was completed using PRISMA guidelines to evaluate the potential complications of DVT prophylactic options. Level one evidence currently supports the use of low molecular weight heparins for thromboprophylaxis in the trauma patient. Unfortunately, multiple techniques are not infrequently required for complex multisystem trauma patients. Each modality has potential complications. The risks of heparin include bleeding and heparin induced thrombocytopenia. Mechanical compression devices can result in local soft tissue injury, bleeding and patient non-compliance. Inferior vena cava filters migrate, cause inferior vena cava occlusion, and penetrate the vessel wall. While the use of these techniques can be life saving, they must be appropriately utilized.
\end{abstract}

\section{Introduction}

Multisystem traumatic injury is a significant risk factor for the development of a deep venous thrombosis (DVT). Without thromboprophylaxis, overall DVT rates exceed 50\% [1-3]. Although DVT alone is not life-threatening, a resulting pulmonary embolism (PE) carries potentially significant morbidity and mortality. PE is estimated to be the third leading cause of death in injured patients who survive beyond the first day of admission [2,4-6]. Trauma patients at the highest risk have been identified as those with a lower extremity or pelvic fracture, spinal cord injury, brain injury (Glasgow Coma Score $<8$ ), increased age, surgical intervention, femoral central venous catheter, and prolonged immobilization [2,3,7-9].

Modalities available for trauma patient thromboprophylaxis are classified into pharmacologic anticoagulation, mechanical compression devices, and inferior vena cava (IVC) filtration. Although the options are numerous, level one evidence currently supports the use of pharmacologic anticoagulation with low molecular

\footnotetext{
* Correspondence: ball.chad@gmail.com

'Department of Surgery, University of Calgary, Calgary, Canada
}

weight heparins (LMWHs) as the primary DVT prophylactic agent [10]. Other modalities such as mechanical compression devices and IVC filters are not used for primary thromboprophylaxis, but may be helpful when LMWHs are contraindicated. This systematic review describes the potential complications associated with LMWHs, mechanical compression devices, and IVC filters.

\section{Methods}

All scientific publications discussing the use of biochemical, mechanical, and IVC filter prophylaxis for the prevention of DVT after trauma were identified using PubMed, EMBASE, and Medline. Search terms included: "DVT", "deep venous thrombosis", "complications", "trauma", "injury", "DVT prophylaxis", "low molecular weight heparin", "heparin", "chemical", "mechanical", "IVC filter" and/or "heparin-induced thrombocytopenia." The Preferred Reporting Items for Systematic reviews and Meta-Analyses (PRISMA) was employed. Only English language publications were included. Once identified, manuscripts were reviewed for relevance to the topic of DVT prophylaxis, and sorted according to their prophylactic mode of choice. This review included all 
trauma related studies (qualitative and quantitative analysis), as well as some publications describing nontrauma patients (qualitative comparisons). More specifically, 274 publications were identified through database searching. After removing non-English and duplicate manuscripts, 268 publications were available for potential analysis. Of these, 26 publications explicitly described an analysis/reporting of potential complications secondary to DVT prophylaxis techniques in an injured patient population. These 26 manuscripts were included in a quantitative synthesis/review. An additional 53 publications were also included in the review for qualitative discussion (non-trauma patients). Pooled data was limited to complication risks for each modality. Clinical heterogeneity was unavoidable across studies with the most significant variance potentially due to the severity of injury in blunt injured patients. Because it is unknown if injury severity affects associated DVT prophylaxis complication rates, pooled summary data was not adjusted. We believe this offers a more broad analysis.

\section{Low Molecular Weight Heparins}

LMWHs are generated from the chemical depolymerization of unfractionated heparin (UH). This reduces their size, charge, and weight [11]. Both LMWHs and UHs inhibit thrombin (IIa), however LMWHs have significantly greater activity towards factor Xa secondary to their smaller size [11]. LMWHs are also less likely to exhibit non-specific binding to endothelium, macrophages, and heparin-binding plasma proteins [11], thereby increasing their bioavailability and half-life. Finally, they also reduce the incidence of heparininduced thrombocytopenia (HIT), and provide a more predictable dose-dependent response.

In trauma patients with a minimal injury severity score (ISS) of 9, and without intracranial hemorrhage, ongoing bleeding or coagulopathy, level one evidence supports the use of enoxaparin (LMWH) as the primary DVT prophylactic modality. In randomizing 265 patients to receive either enoxaparin or UH, Geerts et al. [10] demonstrated a significant reduction in all DVT rates from $44 \%$ to $31 \%$, as well as in proximal DVTs from $15 \%$ to $6 \%$, with the use of enoxaparin. When stratifying patients based on the presence of lower extremity fractures however, only the fracture group displayed significantly reduced proximal DVT rates (5\% compared to 18.2\%) while using enoxaparin. Because proximal DVTs are associated with the majority of risk for PE, this study suggests that in multisystem trauma, the benefit of enoxaparin in preventing PE is mainly reserved for those patients with lower extremity fractures. Current American College of Chest Physicians (ACCP) practice guidelines recommend LMWHs as soon as possible in the absence of intracranial hemorrhage, uncontrolled bleeding or incomplete spinal cord injury with an associated hematoma [12].

Many clinicians still consider intracranial hemorrhage (ICH) to be a contraindication for LMWH DVT prophylaxis. Denson and colleagues noted a $25 \%$ risk of VTE in traumatic brain injured patients however, highlighting the need for adequate prophylaxis. Studies by Kurtoglu et al. [13] and Norwood et al. [14] have also challenged this dogma by demonstrating that enoxaparin can be safely used for DVT prophylaxis in patients with ICH. A recently published prospective trial by Cothren el al. [15] confirms this belief. This group demonstrated the safety of LMWHs in head injury patients without exacerbating intracranial bleeding. Complications associated with LMWHs include bleeding and HIT.

\section{Bleeding}

Hemorrhagic complications of LMWH DVT prophylaxis are varied. They range from a transient decrease in hemoglobin levels to clinical bleeding requiring intervention (angiography or surgery). These complications are poorly defined in the literature and typically categorized into two groups: fatal and non-fatal.

It has been suggested that LMWH increases the rate of major bleeding during DVT prophylaxis. This was not statistically supported by Geerts et al. [10] in spite of the observation that patients receiving $\mathrm{UH}$ had fewer major bleeding episodes compared to LMWHs (0.6\% vs. $2.9 \%$ respectively). Bleeding was considered major when it resulted in a hemoglobin drop of 2 or more grams per deciliter, or more than two units of packed red blood cells were transfused [10]. If a patient required surgery as a consequence of DVT prophylaxis, or had either an intracranial or retroperitoneal bleeding episode, it was also considered major [10]. In contrast, a recent meta-analysis of 20,523 patients [16] showed that LMWHs had fewer major bleeding events when compared to both UHs and pentasaccharide, with relative risks of 1.52 (95\% CI, $1.04-2.23)$ and 1.52 (95\% CI, 1.11 - 2.09) respectively. Only warfarin was observed to have fewer major bleeding events than LMWHs (relative risk $=0.59(95 \% \mathrm{CI}, 0.44-0.8))$. The limitation of this study however, was its inclusion of a mixed patient population. As a result, the authors were unable to draw direct conclusions regarding the LMWH bleeding risk in trauma patients.

LMWHs and UHs were directly compared in three publications. Green et al. [17] observed non-fatal bleeding rates for $\mathrm{LMWH}$ and $\mathrm{UH}$ of $0 \%$ and $9.5 \%$ respectively. They also reported 2 patients (9\%) who died of massive PE in the UH group, versus 0 patients in the LMWH cohort. The overall event (bleeding or thrombosis) rate was $0 \%$ in the LMWH group and $34 \%$ in the $\mathrm{UH}$ group [17]. In contrast, Geerts et al. [10] 
demonstrated bleeding rates for LMWHs and UHs of $2.9 \%$ and $0.6 \%$ respectively. There were no episodes of fatal hemorrhage. In the Spinal Cord Injury Thromboprophylaxis Investigators study, [18] the bleeding rate for $\mathrm{LMWH}$ and $\mathrm{UH}$ was $2.6 \%$ and $5.3 \%$ respectively. Using logistic regression analysis they identified age greater than 50, low baseline hemoglobin, and shorter duration of anticoagulant prophylaxis as predictive of major bleeding events. Differences between the study groups (polytrauma versus spinal cord injury patients) may explain these varied rates (Table 1).

Among the trauma literature, there were six randomized trials [10,13,17-20] comparing LMWHs to other DVT prophylactic agents. All studies explicitly reported bleeding complications. The pooled bleeding risk of $3.9 \%$ was slightly higher than the $3.1 \%$ reported in a meta-analysis by Velmahos et al. [9]. In the same meta- analysis the pooled calculated risk of bleeding using UHs was comparable to LMWHs at $3.6 \%$.

Although enoxaparin was the primary LMWH employed in these studies, the trauma populations were mixed, with some manuscripts analyzing spinal cord trauma cohorts while others investigated general multisystem trauma patients. When these publications were analyzed separately, the pooled bleeding risk for spinal cord trauma patients was $2.6 \%$ compared to $4.7 \%$ for multi-system trauma patients. There were no episodes of fatal bleeding reported in any study employing LMWH DVT prophylaxis.

\section{Heparin Induced Thrombocytopenia}

HIT is an immune-mediated aggregation of platelets leading to thrombocytopenia which has a high association with the development of arterial and venous thrombosis. It is termed HIT, or previously white clot

Table 1 Summary of Randomized LMWH Trauma Studies which Report Bleeding Complications

\begin{tabular}{|c|c|c|c|c|c|}
\hline Study & Design & $\begin{array}{l}\text { Type of } \\
\text { LMWH }\end{array}$ & $\begin{array}{c}\text { No. } \\
\text { Patients }\end{array}$ & $\begin{array}{l}\text { Non-Fatal } \\
\text { Bleeding }\end{array}$ & $\begin{array}{c}\text { Fatal } \\
\text { Bleeding }\end{array}$ \\
\hline \multirow[t]{3}{*}{ Geerts et al. 1996[10] } & Randomized & & & & \\
\hline & $\begin{array}{l}\text { UH 5,000 U SC BID vs. LMWH } 30 \text { mg } \\
\text { SC BID }\end{array}$ & Enoxaparin & $171^{*}$ & $5(2.9 \%)$ & 0 \\
\hline & Multi-system trauma \& ISS $\geq 9$ & & & & \\
\hline \multirow[t]{3}{*}{ Knudson et al. 1996[20] } & Randomized & & & & \\
\hline & $\begin{array}{l}\text { LMWH } 30 \text { mg SC BID vs. SCD or AVI } \\
\text { bilaterally }\end{array}$ & Enoxaparin & 120 & $6(5 \%)$ & 0 \\
\hline & $\begin{array}{c}\text { Multi-system trauma \& AIS } \geq 3 \text { with ISS } \\
\qquad>10\end{array}$ & & & & \\
\hline \multirow[t]{4}{*}{ Ginzburg et al. 2003[19] } & Randomized & & & & \\
\hline & LMWH 30 mg BID vs. IPC bilaterally & Enoxaparin & 218 & $13(6 \%)$ & 0 \\
\hline & Multi-system trauma \& ISS $\geq 9$ & & & & \\
\hline & Multi-sys & tem Trauma & eding Risk & $24 / 509(4.7 \%)$ & $0 \%$ \\
\hline \multirow[t]{3}{*}{ Green et al. 1990[17] } & Randomized & & & & \\
\hline & $\begin{array}{l}\text { UH 5,000 U SC TID vs. LMWH } 3500 \text { U } \\
\text { SC QD }\end{array}$ & Logiparin & 20 & 0 & 0 \\
\hline & $\begin{array}{c}\text { Spinal cord trauma \& complete motor } \\
\text { paraylsis }\end{array}$ & & & & \\
\hline
\end{tabular}

Spinal Cord Injury Thromboprophylaxis Investigators 2003[18]
Randomized

\begin{tabular}{|c|c|c|c|c|c|}
\hline & $\begin{array}{l}\text { UH 5,000 U SC TID + IPC vs. LMWH } 30 \\
\text { mg SC BID }\end{array}$ & Enoxaparin & 230 & $6(2.6 \%)$ & 0 \\
\hline & Spinal cord trauma & & & & \\
\hline Kurtoglu et al. 2004[13] & Randomized & & & & \\
\hline & $\begin{array}{l}\text { LMWH } 40 \text { mg QD vs. IPC bilaterally } \\
\text { Head and Spinal Trauma }\end{array}$ & Enoxaparin & 60 & $2(3.3 \%)$ & 0 \\
\hline & Spina & ord Trauma & ling Risk & $8 / 310(2.6 \%)$ & $0 \%$ \\
\hline & Com & ined Total & ing Risk & $32 / 819$ (3.9\%) & $0 \%$ \\
\hline
\end{tabular}

Kurtoglu et al. 2004[13]

* 344 patients randomized and assessed for bleeding whereas only 265 patients had venograms adequate for DVT analysis ISS, Injury Severity Score; SCD, Sequential Compression Device; IPC, Intermittent Pneumatic Compression 
syndrome, when thrombosis occurs. HIT typically occurs between days 4 and 14 of heparin treatment. Potentially fatal consequences, if not detected early, may include thromboemolism, PE and bleeding [21]. The HIT mechanism involves the development of IgG class antibodies that bind heparin-platelet factor 4 (PF4) complexes [22,23]. This antigen-antibody complex is thought to mediate new thrombi formation and platelet consumption.

The diagnosis of HIT consists of both clinical (thrombocytopenia) and serum detection (HIT antibodies). Although the classic diagnosis of clinically significant thrombocytopenia was a decrease in platelets below 150 $\times 10^{9} / \mathrm{L}$, this definition may be inaccurate in the postoperative or trauma patient population because they often develop an acute phase reaction thrombocytosis. The identification of corresponding antibodies also does not guarantee a diagnosis of HIT because of its poor specificity. Consequently, the latest definition [24] states that clinically significant HIT occurs with an unexplained platelet decrease of over $50 \%$, even when the platelet count is greater than $150 \times 10^{9} / \mathrm{L}$.

The incidence of developing HIT is variable depending on both the duration of treatment and the patient population. More specifically, the highest risk appears to occur in cardiovascular surgery patients [25-28]. A recent study by Lindhoff-Last et al. demonstrated the incidence of HIT during the short-term use (5 to 7 days) of LMWHs to be $0 \%$, whereas the rate was $0.53 \%$ in the UH group [21]. A second cohort of patients treated long-term (28 days) with LMWHs also demonstrated a $0.53 \%$ HIT incidence, similar to the UH group. Warkentin et al. [29] randomized patients to either
LMWH (Enoxaparin) or UH DVT prophylaxis after hip replacement surgery. This demonstrated a statistically significant lower risk of HIT in patients on LMWH when compared to $\mathrm{UH}$, ( $0 \%$ versus $2.7 \%$ respectively). When the modern definition of HIT was applied to this study, the incidence of HIT for LMWH and UH changed to $0.6 \%$ and $4.8 \%$ respectively [24]. Lubenow et al. [30] also identified a $0 \%$ incidence of HIT amongst 460 patients treated with LMWHs.

Although several studies have analyzed LMWHs in the trauma population, few report the incidence of HIT. Three publications $[10,31,32]$ explicitly reported this incidence during LMWH DVT prophylaxis in injured patients. In this review, the pooled calculated rate of HIT was $0.4 \%$ and therefore equal to the rate of $0.4 \%$ reported by Velmahos et al. [9] in a recent meta-analysis. In the meta-analysis, the pooled rate of HIT using UH was $1.9 \%$ [9]. There were also two episodes of HIT resulting in proximal vein thrombi identified by Geerts et al. [10]. Unfortunately one study included in the pooled calculation of this review is retrospective, [32] making our analysis difficult. Furthermore, the original raw data summarized in each manuscript is also not available. Despite the minimal risk for HIT during LMWH DVT prophylaxis, it is important that clinicians follow platelet levels regularly in the care of injured patients (Table 2).

\section{Mechanical Device Complications}

Mechanical device DVT prophylaxis is commonly utilized in the setting of trauma because of its ease of use and inherently low risk of associated bleeding. Mechanical devices include graduated compression stockings

Table 2 Summary of LMWH Trauma Studies Explicitly Reporting Incidence of HIT

\begin{tabular}{|c|c|c|c|c|}
\hline Study & Design & Type of LMWH & No. Patients & No. Cases of HIT \\
\hline \multirow[t]{3}{*}{ Geerts et al. 1996[10] } & Randomized & & & \\
\hline & UH 5,000 U SC BID vs. LMWH 30 mg SC BID & Enoxaparin & 171 & 2 \\
\hline & Multi-system trauma \& ISS $\geq 9$ & & & \\
\hline \multirow[t]{3}{*}{ Haentjens et al. 1996[31] } & Randomized & & & \\
\hline & Fixed LMWH dose vs. Dose Adjusted LMWH & Nadroparin & 283 & 2 \\
\hline & Orthopedic Trauma & & & \\
\hline \multirow[t]{3}{*}{ Schwarcz et al. $2001[32]$} & Retrospective & & & \\
\hline & LMWH 30 mg SC BID & Enoxaparin & 234 & 1 \\
\hline & Multi-system trauma & & & \\
\hline \multirow[t]{4}{*}{ Lubenow et al. 2007[30] } & Prospective cohort & Certoparin & 460 & 0 \\
\hline & LMWH 3000u OD & & & \\
\hline & Multi-system trauma \& orthopedic surgery & & & \\
\hline & Total & & & $5 / 1148(0.4 \%)$ \\
\hline
\end{tabular}

HIT, Heparin Induced Thrombocytopenia 
(GCS), intermittent pneumatic compression (IPC) stockings and the venous foot pump (VFP). All three variations function by reducing the luminal diameter of a vein resulting in an increase in venous flow velocity. This increase in velocity theoretically reduces stasis and decreases the risk of thrombus formation [33].

Compression devices are designed to apply pressure in either a uniform or graduated fashion. Graduated stockings offer a milking action to the leg and apply greatest compression at the ankles. GCS provide a slightly longer augmentation period, but there is no difference in peak venous flow velocity between GCS and uniform compression devices [34]. Despite a suggestion that GCS may provide superior prophylaxis, they have not been reported in the trauma population. IPC however, have been studied in a randomized trial comparing IPC to VFP in injured patients [35]. After randomizing 149 patients without lower extremity fractures, the authors demonstrated a statistically significant decrease in the incidence of DVT using IPC stockings as compared to VFP (6.5\% versus $21 \%$ ). As a result, VFP appears to play no role for DVT prophylaxis in trauma patients.

Two randomized trials also compared LMWHs to mechanical device DVT prophylaxis $[19,20]$. Although the incidence of DVT in the mechanical device groups appeared higher when compared the LMWH cohorts, a statistically significant DVT reduction was not identified. Both studies conclude that mechanical devices are safe and should be considered when anticoagulant DVT prophylaxis is contraindicated.

Although frequently utilized for DVT prophylaxis, no mechanical prophylaxis device has been shown to reduce the rates of VTE or death. A recent trauma meta-analysis by Velmahos failed to show any benefit of IPC stockings compared to no prophylaxis [9]. Similarly, a formal comparison between mechanical devices and IVC filters has yet to be completed. Due to the lack of level one evidence, ACCP guidelines recommend against routine mechanical DVT prophylaxis in trauma patients [12]. They may be considered in patients with a contraindication to anticoagulant VTE prophylaxis however [12]. If mechanical devices are utilized, it is recommended that either IPC or GCS be applied, since VFP have demonstrated higher rates of associated DVTs [35].

Compression stockings are considered safer than pharmacologic DVT prophylaxis because they minimize bleeding risks. Despite a relatively low complication profile, mechanical devices can still be associated with local tissue injury, bleeding, and non-compliance.

\section{Local Tissue Injury}

The possibility of impairing subcutaneous tissue oxygenation, particularly if patients suffer from peripheral vascular compromise, has been previously identified [33]. Stockings of incorrect size may also place focal pressure on skin resulting in tissue necrosis and ulceration. It has been suggested that compression devices are relatively contraindicated in patients with peripheral arterial disease and in diabetics suffering from peripheral neuropathy. In fact, manufactures indicate that compression devices should only be used if patients have ankle:brachial indices greater that 0.7 [33].

Knudson et al. [20] has been the only group to report local tissue damage data as a complication of IPC stockings in trauma patients. Although they did not observe pressure sores or ulceration, four patients had local skin changes. This represents a rate of $2 \%$. The rarity of these reports suggests that this is either a rare event, or under-appreciated. Four cases of peroneal nerve injury associated with mechanical compression device DVT prophylaxis have also been identified [36-38]. The proposed mechanism of injury is nerve compression against the fibular head. Although compartment syndrome is a known complication among patients undergoing surgery in the lithotomy position $[36,39,40]$, there have been no reports in trauma patients.

\section{Bleeding}

Bleeding is considered a rare complication of mechanical DVT prophylaxis. Although the exact mechanism by which mechanical devices cause bleeding is unclear, it is postulated that activation of the fibrinolytic pathway induces clot breakdown. It is also possible that the bleeding events may have occurred regardless of mechanical device use, and are therefore a reflection of baseline risks. Three randomized trauma studies $[13,19,20]$ reported bleeding events in the mechanical device group when compared to LMWHs. As a result, mechanical devices have a lower calculated risk of bleeding (2.6\% vs. $4.7 \%$ )(Table 3 ).

\section{Non-Compliance}

Non-compliance is an indirect complication of mechanical device DVT prophylaxis because it minimizes the intended therapeutic effect. Several studies have demonstrated poor compliance, from both patients and medical staff. In 1992, Comerota et al. [41] performed a prospective study of 138 ICU patients considered high risk for DVT. They demonstrated that $78 \%$ of patients were compliant with mechanical device prophylaxis during their ICU admission, however only $48 \%$ were compliant when transferred to non-monitored units.

In the trauma population, Cornwell et al. [42] performed a prospective analysis of patient compliance using sequential compression device DVT prophylaxis. They performed 6 observations over a 24-hour period (morning, evening and overnight) for 227 high risk nonambulatory trauma patients. Full compliance was defined as compression device use in all 6 observations. They demonstrated only $19 \%$ of patients were fully compliant and that the devices functioned correctly in only 
Table 3 Summary of studies reporting bleeding events with mechanical device thromboprophylaxis

\begin{tabular}{|c|c|c|c|c|}
\hline Study & Design & No. of Patients with IPC & Non Fatal Bleeding Rate & Fatal Bleeding Rate \\
\hline \multirow[t]{3}{*}{ Knudson et al. 1996[20] } & Randomized & 61 & $0 \%$ & $0 \%$ \\
\hline & SCD vs. LMWH 30 mg SC BID & & & \\
\hline & Multi-system trauma, ISS > 10 & & & \\
\hline \multirow[t]{3}{*}{ Ginzburg et al. 2003[19] } & Randomized & 224 & $8(3.5 \%)$ & $0 \%$ \\
\hline & IPC vs. LMWH 30 mg SC BID & & & \\
\hline & Multi-system trauma, ISS $\geq 9$ & & & \\
\hline \multirow[t]{3}{*}{ Kurtoglu et al. 2004[13] } & Randomized & 60 & $1(1.7 \%)$ & $0 \%$ \\
\hline & IPC vs. LMWH 40 mg SC QD & & & \\
\hline & Head \& Spinal Trauma & & & \\
\hline \multicolumn{2}{|c|}{ Total } & 345 & $9(2.6 \%)$ & $0 \%$ \\
\hline
\end{tabular}

$53 \%$ of all observations. Mid morning and early afternoon were associated with the poorest compliance. Furthermore, during the periods of non-compliance, $61 \%$ of patients were awake. Patient and staff education may improve mechanical device VTE prophylaxis compliance [43].

\section{Inferior Vena Cava Filter Complications}

Pharmacologic and mechanical compression device DVT prophylaxis can infrequently be contraindicated in the trauma population. Pharmacologic prophylaxis is contraindicated in patients with intracranial hemorrhage, bleeding solid organ injuries, recent spinal cord damage, and ocular trauma. Furthermore, approximately onethird of multi-system trauma patients suffer lower extremity injuries precluding the use of mechanical compression devices. As a result, permanent prophylactic inferior vena cava (IVC) filters have demonstrated a decreased pulmonary embolism rate in a selected highrisk trauma population [6,44-49]. Unfortunately all but one study [47] were retrospective, and only two reported long-term outcomes and complications [46,49].

In 2004, ACCP guidelines recommended against the use of IVC filters as primary DVT prophylaxis. These recommendations suggested IVC filter placement only in patients with documented proximal DVT and an absolute contraindication to full dose anticoagulation therapy, or planned major surgery in the near future. The absence of a well powered, randomized clinical trial in the trauma population, as well as the unknown frequency of long term complications (i.e. filter migration, vena caval occlusion, and IVC penetration), have limited the use of permanent prophylactic IVC filters.

A randomized trial by Decousus et al. [50] analyzed the efficacy of permanent IVC filters in preventing PE in non-trauma patients with known proximal DVT. Observed short-term benefits in preventing PE were unfortunately offset by long-term complications. This reality has lead to an increased interest in temporary and retrievable IVC filters. These devices offer the immediate benefits of caval filtration when patients are at their highest risk, but can be removed to prevent long-term complications. Since 1986 [51] when the first successful report of a retrievable IVC filter was published, several studies have described success using temporary IVC filters. Given that the majority of the trauma population is young, the ability to remove the filters and avoid potential long-term complications has made them all the more attractive. Recent prospective [52,53] and retrospective [54,55] studies suggest retrievable IVC filters are safe and effective in preventing PE in high risk trauma patients. Until sufficient evidence outlining their efficacy and cost-effectiveness is available however, they will likely remain contraindicated for routine prophylaxis in the AACP guidelines [12]. Although routine use is not indicated, a significant portion of trauma patients will still require placement of these devices when other forms of prophylaxis are contraindicated.

Complications related to IVC filter use fall into short and long-term groups. Short term complications occur during filter insertion, while long term complications arise from the filter itself, as well as its chronic effects on surrounding vasculature and blood flow (Table 4).

\section{Permanent Filter Complications}

Permanent filters are rarely indicated in the trauma population due to the advent of retrievable filters, as well as their ability to be converted to permanent filters if required. However, since retrievable filter studies have limited long term follow-up on patients with retrievable filters converted to permanent, the majority of our understanding of long term complications comes as a result of permanent IVC filter studies.

\section{i. Filter Migration}

Filter migration is defined as cranial or caudal migration greater than $10 \mathrm{~mm}$ [56]. In a long term study [57] 69 patients with permanent IVC filters in place for 1 to 9 
Table 4 List of Short and Long Term IVC Filter Complications

\begin{tabular}{cc}
\hline Short Term Complications & Long Term Complications \\
\hline Inability to cannulate vein & Filter migration \\
Arterial Puncture & Filter tilting \\
Hematoma & Filter strut fracture \\
Hemorrhage & IVC perforation by struts \\
Air embolism & IVC thrombosis \\
Pneumothorax & Lower extremity swelling from venostasis \\
Hemothorax & \\
Wound infection & \\
Insertion site thrombosis & \\
Misplaced filter & \\
IVC perforation & \\
\hline
\end{tabular}

years were evaluated by supine radiographs. Caudal and cranial filter migrations were observed in $29 \%$ and $6 \%$ of patients respectively. Although migration appears to be a common event, its clinical significance is unclear. Many studies have defined clinically significant filter migration as those that became symptomatic. If a patient develops a PE concurrent to filter migration, they are also considered symptomatic. Cranial migration can be symptomatic if it results in an acute myocardial infarction secondary to movement into the right atrium. Caudal migration is only significant when the filter moves to the iliac vein resulting in less protection and a symptomatic PE [58]. In a large single center 26 year review of 1,753 patients (11.9\% trauma) with permanent IVC filters, Athanasoulis et al. [58] reported a symptomatic filter migration rate of $0.5 \%(9 / 1,753)$. Twentytwo percent of these devices (2/9) migrated to the right atrium. Both right atrial filters were retrieved percutaneously while a second filter was placed above the primary filter in the remaining 7 migrations. Routine follow-up radiography was not performed to screen for migration, therefore this rate is likely an underestimate.

In the trauma literature, five studies $[46,47,49,59,60]$ report long-term complications of permanent IVC filters. The overall calculated migration rate is $1.5 \%$ (Table 5 ), which is significantly higher than the $0.5 \%$ rate reported in the largest non-trauma series. Although this appears to be a relatively rare event, reported rates are likely an underestimation because none of these studies performed routine radiographic imaging to screen for filter migration.

\section{ii. IVC Occlusion}

IVC occlusion secondary to thrombosis or trapped emboli can lead to venostasis with lower extremity swelling. It can also progress to hemodynamic instability. Reported rates are variable ( $0.4 \%$ to $32.1 \%)$ and depend upon the type of filter [58], patient population, and time of investigation.

In the trauma literature, Greenfield et al. [59] reported initial IVC occlusion rates between $2.3 \%$ and $3.5 \%$ for therapeutic and prophylactic filters respectively. At the last follow-up (mean $=2.1$ years), IVC occlusion was $0 \%$ and $1.4 \%$ respectively, suggesting IVC patency improves over time. Similar observations in trauma patients by both Patton et al. [60] and Langan et al. [46] identified IVC occlusion rates of $0 \%$. It must be noted however, that these two studies are limited by a considerable loss of patient follow-up (only $34 \%$ and $47 \%$ of patients returned for evaluation). In a five year study of prophylactic trauma IVC filters, Rogers et al. [49] reported 1, 2,

Table 5 Summary of Studies Reporting Permanent IVC Filters Complications in a Trauma Population

\begin{tabular}{|c|c|c|c|c|c|c|}
\hline Study & Filter Type & No. Patients & $\begin{array}{c}\text { Insertion } \\
\text { Complications* }\end{array}$ & $\begin{array}{c}\text { Filter } \\
\text { Migration } \\
\end{array}$ & $\begin{array}{c}\text { Caval } \\
\text { Occlusion }\end{array}$ & $\begin{array}{c}\text { IVC } \\
\text { Penetration }\end{array}$ \\
\hline \multirow{2}{*}{$\begin{array}{l}\text { Greenfield et al. } 2000 \\
\text { [59] }\end{array}$} & 53\% - Titanium GF & 385 - Initial & $24 / 385(6 \%)$ & $6 / 293(2 \%)$ & $7 / 293(2.4 \%)$ & $2 / 293(0.6 \%)$ \\
\hline & $47 \%$ - Stainless Steel GF & $\begin{array}{l}293-\text { Follow- } \\
\text { up }\end{array}$ & & & & \\
\hline \multirow[t]{2}{*}{ Patton et al. 1996[60] } & 100\% - Titanium GF & 110 - Initial & $8 / 110(7 \%)$ & $1 / 110(0.9 \%)$ & $0 / 30(0 \%)$ & - \\
\hline & & 30 - Follow-up & & & & \\
\hline \multirow[t]{2}{*}{ Langan et al. 1999[46] } & $\begin{array}{l}\text { Titanium (not reproted } \\
\% \text { ) }\end{array}$ & 187 - Initial & $3 / 187(1.6 \%)$ & 0/75 (0\%) & 0/70 (0\%) & $1 / 70(1.4 \%)$ \\
\hline & Stainless Steel & 75 - Follow-up & & & & \\
\hline \multirow[t]{4}{*}{ Rogers et al. 1998[49] } & 70\% - Titanium GF & 132 -Initial & 4/132 (3\%) & - & $1 / 47(2 \%)$ & - \\
\hline & $16 \%$ - Stainless Steel GF & 47 - Follow-up & & & & \\
\hline & 8\% - Vena Tech Filter & & & & & \\
\hline & $6 \%$ - Bird's Nest Filter & & & & & \\
\hline $\begin{array}{l}\text { Rodriguez et al. } 1996 \\
\text { [47] }\end{array}$ & 100\% - Titanium GF & 40 - Total & - & - & $4 / 40(10 \%)$ & - \\
\hline TOTAL & & & $39 / 814$ (4.8\%) & 7/473 (1.5\%) & $12 / 480(2.5 \%)$ & $3 / 363(0.8 \%)$ \\
\hline
\end{tabular}

*Insertion Complications: Hematoma, Insertion Site DVT, Arterial Puncture, Pneumothorax, Misplaced IVC Filter, Deployment Errors, Puncture Site Infection Note: GF = Greenfield Filter 
and 3-year IVC patency rates of $97 \%$. The highest rate of IVC occlusion was reported by Rodriguez et al. [47] who documented $10 \%$ of trauma patients (10/40) with thrombi, although only $20 \%(2 / 10)$ were symptomatic secondary to venostasis. Although IVC occlusion rates appear relatively high in the short-term $(2.3 \%$ to $10 \%)$, the reduced long term rates $(0 \%$ to $1.4 \%)$ suggest that this is a rare long-term complication of permanent IVC filtration.

\section{iii. IVC Penetration}

Filter struts possess the ability to erode through the IVC wall inducing free perforation or contact with another organ. Filter erosion appears to be dependent upon the type of filter used. A study analyzing the Simon Nitinol permanent filter by Poletti et al. [61] demonstrated that $95 \%$ of filter struts penetrated the IVC wall and $76 \%$ contacted adjacent organs at 32 months follow-up. In a small study evaluating Bird's Nest Filters by Starok et al., [62] there was $100 \%$ IVC wall penetration, although all were clinically asymptomatic. The lowest reported IVC penetration rate was by Greenfield et al. [63] which followed 30 patients with a stainless steel Greenfield IVC filter and demonstrated a $30 \%$ strut penetration rate with no obvious clinical sequelae. All filter penetration was diagnosed on CT imaging [63]. Although these studies report no clinical consequences of IVC perforation, Streiff et al. [56] identified that $0.4 \%$ of patients develop symptoms.

Complications of strut perforation are rare, but include duodenal perforation [64], aortic pseudoaneurysm [65], retroperitoneal hematoma [66,67], ureteral injury [68], and ruptured infrarenal aorta [69]. Although early studies demonstrate a surprisingly high strut erosion rate (between $30 \%$ and $100 \%$ ), Kinney et al. [70] recently reported a lower range of $9 \%$ to $24 \%$. Despite these values, the majority of patients remain asymptomatic. This reality questions the significance of filter strut IVC penetration.

\section{Non-Permanent Filters}

There are two categories of non-permanent filters: 1) temporary filters, which are attached to a guide-wire or catheter that protrudes externally and, 2) retrievable filters, which are deployed internally and have no external component. Retrievable filters appear to be more applicable due to their ability to become permanent if required. They also have lower infection rates secondary to the absence of an external component. The majority of complications attributable to retrievable filters are related to insertion since long-term complications are eliminated at the time of filter retrieval. Retrievable filters can become permanent however, and have the added complication of failed retrieval, thus exposing the patient to the long-term complications of permanent IVC filtration.

There are currently three retrievable filters approved by the Food and Drug Administration (FDA): 1) Gunther Tulip (Cook, Inc., Bloomington, Indiana), 2) Recovery Filter (Bard Peripheral Vascular, Inc., Tempe, Arizona), and 3) OptEase (Cordis Endovascular, Warren, New Jersey). Although retrieval time limits have yet to be defined, most filters are removed within a few weeks. The longest reported retrieval time in a trauma patient was 317 days [71]. This retrieval required significant force, with post-retrieval cavography revealing a mildly stenosed IVC. This IVC subsequently returned to prefilter diameter within 3 months. Although there are several studies which explicitly report retrievable filter complications in non-trauma patients, [72-78] only four studies analyzed their role in the trauma population [52,55](Table 6).

Short-term complications of retrievable IVC filters in non-trauma patients occur at a rate of $0 \%$ to $4.5 \%$ [72-74,77,78], with a calculated rate of $2.6 \%$. The six insertion site complications reported by Rosenthal et al. [55] included a femoral vein DVT, three misplaced IVC filters into the right iliac vein, and two groin hemato-

Table 6 Summary of Studies Analyzing Retrievable IVC Filters in a Trauma Population

\begin{tabular}{|c|c|c|c|c|c|c|c|c|}
\hline Study & $\begin{array}{l}\text { Filter } \\
\text { Type }\end{array}$ & $\begin{array}{c}\text { No. } \\
\text { Patients }\end{array}$ & $\begin{array}{l}\text { Duration of Insertion } \\
\text { (mean) (days) (range) }\end{array}$ & $\begin{array}{c}\text { Insertion } \\
\text { Complication* }\end{array}$ & $\begin{array}{c}\text { Filter } \\
\text { Migration } \\
\end{array}$ & $\begin{array}{c}\text { IVC } \\
\text { Penetration }\end{array}$ & $\begin{array}{c}\text { Caval } \\
\text { Occlusion }\end{array}$ & $\begin{array}{c}\text { Failed } \\
\text { Retrieval Rate } \\
\end{array}$ \\
\hline $\begin{array}{l}\text { Rosenthal et al. } \\
\text { 2004[55] }\end{array}$ & Optease & 94 & $19(5-25)$ & $6(6.4 \%)$ & 0 & 1 & 0 & $0 / 31$ \\
\hline $\begin{array}{l}\text { Allen et al. } 2005 \\
\text { [54] }\end{array}$ & $\begin{array}{l}\text { Gunther } \\
\text { Tulip }\end{array}$ & 51 & $N R$ & $0 / 51$ & 0 & 0 & 0 & $1 / 25(4 \%)$ \\
\hline $\begin{array}{l}\text { Offner et al. } \\
\text { 2003[53] }\end{array}$ & $\begin{array}{l}\text { Gunther } \\
\text { Tulip }\end{array}$ & 44 & $14(3-30)$ & $0 / 44$ & 0 & 0 & 0 & $1 / 40(2.5 \%)$ \\
\hline $\begin{array}{l}\text { Hoff et al. } 2004 \\
\text { [52] }\end{array}$ & $\begin{array}{l}\text { Gunther } \\
\text { Tulip }\end{array}$ & 35 & $10(6-14)$ & $0 / 35$ & 0 & 0 & 0 & $0 / 18$ \\
\hline$\overline{\text { TOTAL }}$ & & 224 & & $6 / 224(2.6 \%)$ & 0 & $1 / 224(0.4 \%)$ & 0 & $2 / 114(2.8 \%)$ \\
\hline
\end{tabular}

*Insertion Complications: Hematoma, Insertion Site DVT, Arterial Puncture, Pneumothorax, Misplaced IVC Filter, Deployment Errors, Puncture Site Infection 
mas. This was the only study to experience insertion related complications, however all filters were placed at the bedside under ultrasound guidance.

There is poor long-term follow-up data for trauma patients with retrievable filters that were not removed. In studies involving non-trauma patients with permanent retrievable filters, filter migration occurred between $3 \%$ and $8 \%$, and IVC occlusion rates were reported between $4 \%$ and $15 \%$ [72-75,77,78]. Of the four studies analyzing retrievable filters in injured patients, none reported filter migration or IVC occlusion rates. One patient did have a symptomatic IVC penetration for a calculated rate of $0.4 \%$ however.

Failed filter retrieval does not carry an immediate complication to the patient, but it does expose the patient to the long-term complications of a permanent filter. Failed retrieval rates in trauma patients are reported between $0 \%$ and $4 \%$ with a calculated rate of $2.8 \%$ (Table 6 ).

\section{Conclusion}

Pharmacologic anticoagulation using LMWHs is the recommended primary thromboprophylaxis modality in trauma patients. In this review we calculated the risk of bleeding and HIT to be $3.9 \%$ and $0.7 \%$ respectively. These values are slightly higher than the previously published rates of $3.1 \%$ and $0.4 \%$ [9]. Mechanical compression device thromboprophylaxis should not be used as an initial choice, however evidence supports its role in trauma patients when LMWHs are contraindicated. Mechanical devices have a generally safe profile, however they must be used with caution in patients with peripheral vascular disease and peripheral neuropathy for risks of soft tissue injury and ulceration. Although the mechanism that predisposes patients to bleeding while using mechanical devices is unclear, the calculated risk of bleeding is $2.6 \%$. This may reflect the general risk of bleeding in a trauma patient. Patient compliance is poor but may be improved with adequate patient and staff education regarding the benefits of mechanical thromboprophylaxis. When LMWH and mechanical device thromboprophylaxis are contraindicated, retrievable IVC filters should be considered in high-risk trauma patients [79]. Current high risk features include: spinal cord injury with paraplegia or tetraplegia, severe brain injury (Glascow Coma Score $<8$ ), multiple long bone fractures and complex pelvic fractures [8]. Future studies are needed to identify the trauma populations that will benefit from prophylactic IVC filtration. Retrievable IVC filters have the benefit of providing protection from $P E$ in the early, high-risk period while consequently being removed to prevent the long-term complications of permanent IVC filtration. Although retrievable filters are removed in the majority of patients, they may also be left in place for permanent filtration if necessary. The versatility of the retrievable filter has virtually eliminated the use of permanent filters. Long-term follow-up studies of permanent IVC filtration using retrievable filters are required. The risk of insertion related complications, such as arterial puncture, hematoma, infection, and pneumothorax is calculated to be $2.6 \%$. There were no reported filter migration or IVC occlusion events in the short-term. Although a failed retrieval is not a direct complication, it results in permanent IVC filtration and places the patient at risk for future complications. The failed retrieval rate is calculated to be $2.8 \%$. While the essential nature of thromboprophylaxis in the management of multi-system trauma patients can not be understated, understanding their potential complications is an absolute requirement for both patient counselling and clinical care.

\section{Author details}

${ }^{1}$ Department of Surgery, University of Calgary, Calgary, Canada. ${ }^{2}$ Department of Surgery, University of British Columbia, Vancouver, Canada.

\section{Authors' contributions}

ID - Study design, data analysis, manuscript writing \& editing.

CGB - Data analysis, manuscript writing \& editing.

LRR - Data analysis \& manuscript writing.

SMH - Data analysis, manuscript writing \& editing.

JBK - Study design, data analysis, manuscript writing \& editing.

All authors read and approved the final manuscript.

\section{Competing interests}

The authors declare that they have no competing interests.

Received: 2 June 2009

Accepted: 6 January 2010 Published: 6 January 2010

\section{References}

1. Kudsk KA, Fabian TC, Baum S, Gold RE, Mangiante E, Voeller G: Silent deep vein thrombosis in immobilized multiple trauma patients. Am J Surg 1989, 158:515-9.

2. Geerts WH, Code Kl, Jay RM, Chen E, Szalai JP: A prospective study of venous thromboembolism after major trauma. N Engl J Med 1994, 331:1601-6.

3. Geerts WH, Heit JA, Clagett GP, Pineo GF, Colwell CW, Anderson FA Jr, Wheeler HB: Prevention of venous thromboembolism. Chest 2001, 119(1 Suppl):132S-75S

4. Acosta JA, Yang JC, Winchell RJ, Simons RK, Fortlage DA, HollingsworthFridlund $\mathrm{P}$, Hoyt DB: Lethal injuries and time to death in a level I trauma center. J Am Coll Surg 1998, 186:528-33.

5. O'Malley KF, Ross SE: Pulmonary embolism in major trauma patients. $J$ Trauma 1990, 30:748-50.

6. Rogers FB, Shackford SR, Wilson J, Ricci MA, Morris CS: Prophylactic vena cava filter insertion in severely injured trauma patients: indications and preliminary results. J Trauma 1993, 35:637-42.

7. Meissner MH, Chandler WL, Elliott JS: Venous thromboembolism in trauma: a local manifestation of systemic hypercoagulability?. J Trauma 2003, 54:224-31.

8. Rogers FB, Cipolle MD, Velmahos G, Rozycki G, Luchette FA: Practice management guidelines for the prevention of venous thromboembolism in trauma patients: the EAST practice management guidelines work group. J Trauma 2002, 53:142-64.

9. Velmahos GC, Kern J, Chan LS, Odor D, Murray JA, Shekelle P: Prevention of venous thromboembolism after injury: an evidence-based report-part II: analysis of risk factors and evaluation of the role of vena caval filters. J Trauma 2000, 49:140-4. 
10. Geerts WH, Jay RM, Code Kl, Chen E, Szalai JP, Saibil EA, Hamilton PA: A comparison of low-dose heparin with low-molecular-weight heparin as prophylaxis against venous thromboembolism after major trauma. $\mathrm{N}$ Engl J Med 1996, 335:701-7.

11. Weitz Jl: Low-molecular-weight heparins. N Engl J Med 1997, 337:688-98.

12. Geerts WH, Pineo GF, Heit JA, Bergqvist D, Lassen MR, Colwell CW, Ray JG: Prevention of venous thromboembolism: the Seventh ACCP Conference on Antithrombotic and Thrombolytic Therapy. Chest 2004, 126(3 Suppl):338S-400S.

13. Kurtoglu M, Yanar H, Bilsel Y, Guloglu R, Kizilirmak S, Buyukkurt D, Granit V: Venous thromboembolism prophylaxis after head and spinal trauma: intermittent pneumatic compression devices versus low molecular weight heparin. World J Surg 2004, 28:807-11.

14. Norwood SH, McAuley CE, Berne JD, Vallina VL, Kerns DB, Grahm TW, Short K, McLarty JW: Prospective evaluation of the safety of enoxaparin prophylaxis for venous thromboembolism in patients with intracranial hemorrhagic injuries. Arch Surg 2002, 137:696-702.

15. Cothren CC, Smith WR, Moore EE, Morgan SH: Utility of once-daily dose of low-molecular-weight heparin to prevent venous thromboembolism in multisystem trauma patients. World J Surg 2007, 31:98-104.

16. Muntz J, Scott DA, Lloyd A, Egger M: Major bleeding rates after prophylaxis against venous thromboembolism: systematic review, metaanalysis, and cost implications. Int J Technol Assess Health Care 2004 20:405-14.

17. Green D, Lee MY, Lim AC, Chmiel JS, Vetter M, Pang T, Chen D, Fenton L, Yarkony GM, Meyer PR Jr: Prevention of thromboembolism after spinal cord injury using low-molecular-weight heparin. Ann Intern Med 1990, 113:571-4.

18. Spinal Cord Injury Thomboprophylaxis Investigators: Prevention of venous thromboembolism in the acute treatment phase after spinal cord injury: a randomized, multicenter trial comparing low-dose heparin plus intermittent pneumatic compression with enoxaparin. J Trauma 2003, 54:1116-26.

19. Ginzburg E, Cohn SM, Lopez J, Jackowski J, Brown J, Brown M, Hameed SM, Miami Deep Vein Thrombosis Study Group: Randomized clinical trial of intermittent pneumatic compression and low molecular weight heparin in trauma. Br J Surg 2003, 90:1338-44.

20. Knudson MM, Morabito D, Paiement GD, Shackleford S: Use of low molecular weight heparin in preventing thromboembolism in trauma patients. J Trauma 1996, 41:446-59.

21. Lindhoff-Last E, Nakov R, Misselwitz F, Breddin HK, Bauersachs R: Incidence and clinical relevance of heparin-induced antibodies in patients with deep vein thrombosis treated with unfractionated or low-molecularweight heparin. Br J Haematol 2002, 118:1137-42.

22. Amiral J, Bridey F, Wolf M, Boyer-Neumann C, Fressinaud E, Vissac AM Peunaud-Debayle E, Dreyfus M, Meyer D: Antibodies to macromolecular platelet factor 4-heparin complexes in heparin-induced thrombocytopenia: a study of 44 cases. Thromb Haemost 1995, 73:21-8.

23. Amiral J, Wolf M, Fischer A, Boyer-Neumann C, Vissac A, Meyer D: Pathogenicity of IgA and/or IgM antibodies to heparin-PF4 complexes in patients with heparin-induced thrombocytopenia. Br J Haematol 1996 92:954-9.

24. Warkentin TE, Roberts RS, Hirsh J, Kelton JG: An improved definition of immune heparin-induced thrombocytopenia in postoperative orthopedic patients. Arch Intern Med 2003, 163:2518-24.

25. Bauer TL, Arepally G, Konkle BA, Mestichelli B, Shapiro SS, Cines DB, Poncz M, McNulty S, Amiral J, Hauck WW, Edie RN, Mannion JD: Prevalence of heparin-associated antibodies without thrombosis in patients undergoing cardiopulmonary bypass surgery. Circulation 1997, 95:1242-6.

26. Lindhoff-Last E, Eichler P, Stein M, Plagemann J, Gerdsen F, Wagner R, Ehrly AM, Bauersachs R: A prospective study on the incidence and clinical relevance of heparin-induced antibodies in patients after vascular surgery. Thromb Res 2000, 97:387-93.

27. Visentin GP, Malik M, Cyganiak KA, Aster RH: Patients treated with unfractionated heparin during open heart surgery are at high risk to form antibodies reactive with heparin:platelet factor 4 complexes. J Lab Clin Med 1996, 128:376-83.

28. Warkentin TE, Sheppard JA, Horsewood P, Simposn PJ, Moore JC, Kelton JG: Impact of the patient population on the risk for heparin-induced thrombocytopenia. Blood 2000, 96:1703-8.
29. Warkentin TE, Levine MN, Hirsh J, Horsewood P, Roberts RS, Gent M Kelton JG: Heparin-induced thrombocytopenia in patients treated with low-molecular-weight heparin or unfractionated heparin. N Engl J Med 1995, 332:1330-5.

30. Lubenow N, Hinz P, Ekkernkamp A, Greinacher A: Should patients be informed about the risk of heparin-induced thrombocytopenia before prolonged low-molecular-weight heparin thromboprophylaxis posttrauma/orthopedic surgery?. Eur J Haematol 2007, 79:187-90.

31. Haentjens P: Thromboembolic prophylaxis in orthopaedic trauma patients: a comparison between a fixed dose and an individually adjusted dose of a low molecular weight heparin (nadroparin calcium). Injury 1996, 27:385-90.

32. Schwarcz TH, Quick RC, Minion DJ, Kearney PA, Kwolek CJ, Endean ED: Enoxaparin treatment in high-risk trauma patients limits the utility of surveillance venous duplex scanning. J Vasc Surg 2001, 34:447-52.

33. Agu O, Hamilton G, Baker D: Graduated compression stockings in the prevention of venous thromboembolism. Br J Surg 1999, 86:992-1004.

34. Morris RJ, Woodcock JP: Evidence-based compression: prevention of stasis and deep vein thrombosis. Ann Surg 2004, 239:162-71.

35. Elliott CG, Dudney TM, Egger M, Orme JF, Clemmer TP, Horn SD, Weaver L, Handrahan D, Thomas F, Merrell S, Kitterman N, Yeates S: Calf-thigh sequential pneumatic compression compared with plantar venous pneumatic compression to prevent deep-vein thrombosis after nonlower extremity trauma. J Trauma 1999, 47:25-32.

36. Lachmann EA, Rook JL, Tunkel R, Nagler W: Complications associated with intermittent pneumatic compression. Arch Phys Med Rehabil 1992, 73:4825.

37. McGrory BJ, Burke DW: Peroneal nerve palsy following intermittent sequential pneumatic compression. Orthopedics 2000, 23:1103-5.

38. Pittman GR: Peroneal nerve palsy following sequential pneumatic compression. Jama 1989, 261:2201-2.

39. Cohen SA, Hurt WG: Compartment syndrome associated with lithotomy position and intermittent compression stockings. Obstet Gynecol 2001, 97:832-3.

40. Verdolin $\mathrm{MH}$, Toth AS, Schroeder R: Bilateral lower extremity compartment syndromes following prolonged surgery in the low lithotomy position with serial compression stockings. Anesthesiology 2000, 92:1189-91.

41. Comerota AJ, Katz ML, White JV: Why does prophylaxis with external pneumatic compression for deep vein thrombosis fail?. Am J Surg 1992, 164:265-8.

42. Cornwell EE, Chang D, Velmahos G, Jindal A, Baker D, Phillips J, Bonar J, Campbell K: Compliance with sequential compression device prophylaxis in at-risk trauma patients: a prospective analysis. Am Surg 2002, 68:470-3.

43. Haddad FS, Kerry RM, McEwen JA, Appleton L, Garbuz DS, Masri BA, Duncan CP: Unanticipated variations between expected and delivered pneumatic compression therapy after elective hip surgery: a possible source of variation in reported patient outcomes. J Arthroplasty 2001, 16:37-46.

44. Carlin AM, Tyburski JG, Wilson RF, Steffes C: Prophylactic and therapeutic inferior vena cava filters to prevent pulmonary emboli in trauma patients. Arch Surg 2002, 137:521-7.

45. Khansarinia S, Dennis JW, Veldenz HC, Butcher JL, Hartland L: Prophylactic Greenfield filter placement in selected high-risk trauma patients. J Vasc Surg 1995, 22:231-6.

46. Langan EM, Miller RS, Casey WJ, Carsten CG, Graham RM, Taylor SM: Prophylactic inferior vena cava filters in trauma patients at high risk: follow-up examination and risk/benefit assessment. J Vasc Surg 1999, 30:484-88.

47. Rodriguez JL, Lopez JM, Proctor MC, Conley JL, Gerndt SJ, Marx MV, Taheri PA: Early placement of prophylactic vena caval filters in injured patients at high risk for pulmonary embolism. J Trauma 1996, 40:797-804.

48. Rogers FB, Shackford SR, Ricci MA, Wilson JT, Parsons S: Routine prophylactic vena cava filter insertion in severely injured trauma patients decreases the incidence of pulmonary embolism. J Am Coll Surg 1995, 180:641-7.

49. Rogers FB, Strindberg G, Shackford SR, Osler TM, Morris CS, Ricci MA, Najarian KE, D'Astino R, Pilcher DB: Five-year follow-up of prophylactic vena cava filters in high-risk trauma patients. Arch Surg 1998, 133:406-12.

50. Decousus H, Leizorovicz A, Parent F, Page Y, Tardy B, Girard P, Laporte S, Faivre $\mathrm{R}$, Charbonnier B, Barral B, Huet $Y$, Simmonneau G: A clinical trial of vena caval filters in the prevention of pulmonary embolism in patients 
with proximal deep-vein thrombosis. Prevention du Risque d'Embolie Pulmonaire par Interruption Cave Study Group. N Engl J Med 1998, 338:409-15.

51. Darcy MD, Smith TP, Hunter DW, Castraneda-Zuniga W, Lund G, Amplatz K: Short-term prophylaxis of pulmonary embolism by using a retrievable vena cava filter. AJR Am J Roentgenol 1986, 147:836-8.

52. Hoff WS, Hoey BA, Wainwright GA, Reed JF, Ball DS, Ringold M, Grossman MD: Early experience with retrievable inferior vena cava filters in high-risk trauma patients. J Am Coll Surg 2004, 199:869-74.

53. Offner PJ, Hawkes A, Madayag R, Seale F, Maines C: The role of temporary inferior vena cava filters in critically ill surgical patients. Arch Surg 2003, 138:591-5.

54. Allen TL, Carter UL, Morris BJ, Harker CP, Stevens MH: Retrievable vena cava filters in trauma patients for high-risk prophylaxis and prevention of pulmonary embolism. Am J Surg 2005, 189:656-61.

55. Rosenthal D, Wellons ED, Levitt AB, Shuler FW, O'Conner RE, Henderson VJ: Role of prophylactic temporary inferior vena cava filters placed at the ICU bedside under intravascular ultrasound guidance in patients with multiple trauma. J Vasc Surg 2004, 40:958-64.

56. Streiff MB: Vena caval filters: a comprehensive review. Blood 2000, 95:3669-77.

57. Messmer JM, Greenfield L: Greenfield caval filters: long-term radiographic follow-up study. Radiology 1985, 156:613-8.

58. Athanasoulis CA, Kaufman JA, Halpern EF, Waltman AC, Geller SC, Fan CM: Inferior vena caval filters: review of a 26-year single-center clinical experience. Radiology 2000, 216:54-66.

59. Greenfield LJ, Proctor MC, Michaels AJ, Taheri PA: Prophylactic vena caval filters in trauma: the rest of the story. J Vasc Surg 2000, 32:490-7.

60. Patton $\mathrm{JH} \mathrm{Jr}$, Fabian TC, Croce MA, Minard G, Pritchard FE, Kudsk KA: Prophylactic Greenfield filters: acute complications and long-term follow-up. J Trauma 1996, 41:231-7.

61. Poletti PA, Becker CD, Prina L, Rujis P, Bounameaux H, Didier D, Schneider PA, Terrier F: Long-term results of the Simon nitinol inferior vena cava filter. Eur Radiol 1998, 8:289-94.

62. Starok MS, Common AA: Follow-up after insertion of Bird's Nest inferior vena caval filters. Can Assoc Radiol J 1996, 47:189-94.

63. Greenfield LJ, Cho KJ, Tauscher JR: Limitations of percutaneous insertion of Greenfield filters. J Cardiovasc Surg 1990, 31:344-50.

64. Feezor RJ, Huber TS, Welborn MB, Schell SR: Duodenal perforation with an inferior vena cava filter: an unusual cause of abdominal pain. J Vasc Surg 2002, 35:1010-2.

65. Putterman D, Niman D, Cohen G: Aortic pseudoaneurysm after penetration by a Simon nitinol inferior vena cava filter. J Vasc Interv Radiol 2005, 16:535-8.

66. Goldman KA, Adelman MA: Retroperitoneal caval filter as a source of abdominal pain. Cardiovasc Surg 1994, 2:85-7.

67. Miller CL, Wechsler RJ: CT evaluation of Kimray-Greenfield filter complications. Am J Roentgenol 1986, 147:45-50.

68. Goldman HB, Hanna K, Dmochowski RR: Ureteral injury secondary to an inferior vena caval filter. J Urol 1996, 156:1763.

69. Dabbagh A, Chakfe N, Kretz JG, Cemri B, Nicolini P, Fuentes C, Mettauer B, Epailly E, Muster D, Eisenmann B: Late complication of a Greenfield filter associating caudal migration and perforation of the abdominal aorta by a ruptured strut. J Vasc Surg 1995, 22:182-7.

70. Kinney TB: Update on inferior vena cava filters. J Vasc Interv Radiol 2003, 14:425-40.

71. Binkert CA, Bansal A, Gates JD: Inferior vena cava filter removal after 317day implantation. J Vasc Interv Radiol 2005, 16:395-8.

72. Asch MR: Initial experience in humans with a new retrievable inferior vena cava filter. Radiology 2002, 225:835-44.

73. Bovyn G, Gory P, Reynaud P, Ricco JB: The Tempofilter: a multicenter study of a new temporary caval filter implantable for up to six weeks. Ann Vasc Surg 1997, 11:520-8.

74. Millward SF, Bhargava A, Aquino J Jr, Peterson RA, Veinot JP, Bormanis J, Wells PS: Gunther Tulip filter: preliminary clinical experience with retrieval. J Vasc Interv Radiol 2000, 11:75-82.

75. Millward SF, Bormanis J, Burbridge BE, Markman SJ, Peterson RAI: Preliminary clinical experience with the Gunther temporary inferior vena cava filter. J Vasc Interv Radiol 1994, 5:863-8.

76. Millward SF, Oliva VL, Bell SD, Valenti DA, Rasuli P, Asch M, Hadziomerovic A, Kachura JR: Gunther Tulip Retrievable Vena Cava Filter: results from the Registry of the Canadian Interventional Radiology Association. J Vasc Interv Radiol 2001, 12:1053-8.

77. Neuerburg JM, Gunther RW, Vorwerk D, Dondelinger RF, Jager $H_{\text {, }}$ LAckner KJ, Schild HH, Plant GR, Joffre FG, Schneider PA, Janssen JH: Results of a multicenter study of the retrievable Tulip Vena Cava Filter: early clinical experience. Cardiovasc Intervent Radiol 1997, 20:10-6.

78. Wicky S, Doenz F, Meuwly JY, Portier F, Schnyder P, Denys A: Clinical experience with retrievable Gunther Tulip vena cava filters. J Endovasc Ther 2003, 10:994-1000.

79. Kaufman JA, Kinney TB, Streiff MB, Sing RF, Proctor MC, Becker D, Cipolle M, Comerota AJ, Millward SF, Rogers FB, Sacks D, Venbrux AC: Guidelines for the use of retrievable and convertible vena cava filters: Report from the Society of Interventional Radiology multidisciplinary consensus conference. Surg Obes Relat Dis 2006, 2:200-12.

doi:10.1186/1752-2897-4-1

Cite this article as: Datta et al:: Complications related to deep venous thrombosis prophylaxis in trauma: a systematic review of the literature. Journal of Trauma Management \& Outcomes 2010 4:1.

\section{Publish with Biomed Central and every scientist can read your work free of charge}

"BioMed Central will be the most significant development for disseminating the results of biomedical research in our lifetime. "

Sir Paul Nurse, Cancer Research UK

Your research papers will be:

- available free of charge to the entire biomedical community

- peer reviewed and published immediately upon acceptance

- cited in PubMed and archived on PubMed Central

- yours - you keep the copyright
BioMedcentral 